\title{
Presentism, truthmakers and distributional properties
}

\author{
Phil Corkum
}

Received: 16 January 2014 / Accepted: 8 April 2014 / Published online: 24 April 2014

(C) Springer Science+Business Media Dordrecht 2014

\begin{abstract}
Presentists face a challenge from truthmaker theory: if you hold that the only existing objects are presently existing objects and, moreover, you agree that truth supervenes on being, then you will be hard pressed to identify some existent on which a given true but traceless claim about the past supervenes. Cameron (Philos Books 49:292-301, 2008, Oxford Studies in Metaphysics, In: D Zimmerman (ed), 2011) aims to meet this challenge by appeal to distributional properties. So, to give a simple example, the truth that you were once a child supervenes on you presently instantiating the property of being initially a child and then an adult, a property distributed over time. I argue that a presentist ought to deny that distributional properties can serve as truthmakers.
\end{abstract}

Keywords Time $\cdot$ Presentism $\cdot$ Truthmakers $\cdot$ Distributional properties

\section{Introduction}

Presentists face a challenge from truthmaker theory. Roughly, the challenge is this: suppose you hold that only the present time exists, the only existing objects are presently existing objects and the only instantiated properties are presently instantiated properties. Moreover, you agree that truth supervenes on being, so there are no changes in the truths without changes in what exists or what is instantiated. Then you will be hard pressed to identify some object or property on which a given true claim about the past supervenes. Cameron $(2008,2011)$ aims to meet this challenge by appeal to distributional properties. Such properties, first discussed by Parsons (2004), are distributed over an extension: for example, being polka-dotted red on white is a property distributed over a spatial surface; and being initially a child and then an adult is a property

P. Corkum ( $\bowtie)$

Philosophy Department, University of Alberta, 2-40 Assiniboia Hall, Edmonton, AB T6G 2E7, Canada e-mail: phil.corkum@ualberta.ca 
distributed over time. Cameron holds that temporal distributional properties can serve as presently instantiated truthmakers for past truths. So, to give a simple example, the truth that you were once a child supervenes on you presently instantiating the property of being initially a child and then an adult. I shall argue that a presentist ought to deny that distributional properties can serve as presently existing truthmakers for past claims.

\section{The challenge}

I begin by unpacking the challenge that presentists face from truthmaker theory. This will be a familiar story to many readers but some care here will pay dividends down the road. Consider the following two theses.

PRESENTISM Everything is present.

TRUTHMAKER Truth supervenes on being.

The intuition driving PRESENTISM is that the past was but no longer is. The future will be but is not yet. And similarly for objects existing, and properties instantiated, at a time: Caesar existed but does not now exist, and so does not exist simpliciter. So only the present time exists, the only objects that exist are presently existing objects, and the only instantiated properties are those presently instantiated. ${ }^{1}$ PRESENTISM is opposed to such positions as eternalism, the view that all three of the past, present and future exist (or, again, that past, present and future objects all exist), and the growing block theory of time, according to which just the past and present exist (or just past and present objects exist).

The leading idea of truthmaker theory is that what truths there are depends on the way the world is. The original truthmaker theorists such as Armstrong (1997) viewed truthmaking in terms of necessitation: for any true proposition, there is an entity the existence of which suffices for the proposition to be true. But true non-existence claims such as 'There are no unicorns' do not appear to need an existing entity to be true. In response to such objections, Bigelow (1988, pp. 130-133) for example claims merely that truth supervenes on being. Were 'There are no unicorns' false, there would be corresponding differences in ontology. Supervenience is arguably too weak to capture the sense in which an ontology grounds truths. ${ }^{2}$ However, the weakness of TRUTHMAKER is an advantage for us: if PRESENTISM is inconsistent with it, then it is of course inconsistent with stronger formulations of the truthmaker intuition cashed out in terms of necessitation or grounding. I have left TRUTHMAKER underspecified, since differences in formulation between, say, global and local supervenience claims will not affect my argument.

\footnotetext{
${ }^{1}$ For the characterization of PRESENTISM in terms of the existence of times, see for example Armstrong (2004, p. 145) and Bourne (2006, p. 13). For the characterization in terms of presently existing objects, see for example Merricks (1995, p. 523), Mellor (1998, p. 20) and Sider (2001, p. 11). PRESENTISM is vacuously true if the copula in the slogan is present tensed: everything that presently exists is present. For the slogan to state a substantive thesis, we must take the copula to refer to existence simpliciter. For discussion of triviality in the formulation of presentism, see Lombard (1999), Crisp (2004) and Meyer (2005, 2012).

2 And recently some have offered alternative ways to handle negative existential truths: see, for example, Schaffer $(2008,2010)$.
} 
There is a prima facie tension between PRESENTISM and TRUTHMAKER. Take, for example, a true claim about the past, such as the claim that dinosaurs roamed the earth. ${ }^{3}$ Has the presentist available to her a supervenience base for this truth? Suppose for illustration that truths supervene on obtaining states of affairs. Under an attractive view of states of affairs, the past state of affairs that dinosaurs roamed the earth is composed of the dinosaurs themselves and a property of earth-roaming. As such, the state of affairs is itself not presently existing and so, according to the presentist, does not exist. (Similar problems arise for alternative truthmaker candidates.) Some past truths have traces, evidence of those truths. For example, the claim that dinosaurs roamed the earth has traces in the fossil record. However, truths do not supervene on traces, since different past events might have resulted in the same traces. And, for many truths about the past, there are no longer any traces. So traces cannot provide truthmakers for past claims.

Some presentists respond that there are nonetheless presently existing facts or presently instantiated properties that can serve as a supervenience base for past truths. To continue our example, one might hold that there is a present fact that the world contained dinosaurs; or one might hold that the world currently instantiates the property of having previously contained dinosaurs. Following Bigelow (1996), call these brute tensed facts or properties Lucretian. Lucretian facts or properties appear to provide presently existing truthmakers for past claims.

The appeal to Lucretian facts or properties, however, has struck some as a cheat. Sider (2001, p. 41), for example, holds that tensed facts are hypotheticals but truthmakers must be categorical or occurrent, writing: "[w]hether the world has the property previously containing dinosaurs is not a matter of what the world itself is like, but points beyond itself, to the past." How might we develop this prohibition against cheating so to formulate a condition of adequacy for any proposed supervenience base for past truths? The demonstrative imagery in Sider's characterization is evocative but it should not be taken literally. A property merely pointing beyond its instances cannot be the target. For such a requirement wrongly would label legitimate properties as cheaters. If pointing is demonstrative, for example, then the formulation would view many demonstrative properties as cheaters. Except for the special case of de se demonstration, where the demonstrator and that demonstrated are one and the same, demonstrative properties point beyond their instances. But to preclude demonstrations is not the intention of those who endorse a prohibition against cheating. So we must take talk of pointing as metaphorical and at best an intuitive first stab at a prohibition against cheating.

One way of cashing out the prohibition is to draw on the distinction between hypothetical and categorical properties. However, the hypothetical-categorical distinction is but an example of cheating in a certain context. Sider (2001, pp. 40-41) does not claim that hypothetical properties such as dispositions are cheaters, but only that they are cheaters if one is committed to categoricity. For example, brute dispositions are cheaters only if one already holds that "a proper ontology should invoke only categorical, or occurrent, properties and relations." Sider (2001, p. 41) is explicit on this

\footnotetext{
3 For the most part, I shall restrict discussion to the presentist view that the past does not exist. This simplification serves my purposes, avoids irrelevant complications concerning the future, and distinguishes presentism from growing block theorists such as Tooley (1997).
} 
point: "the argument against presentism is not strictly tied to the hypothesis that noncategoricity is to blame. The argument without this claim would simply be that the presentist's primitive tenses [or tensed properties] share some unspecified negative feature with the rejected ontologies."

What then is it for a property to illegitimately point beyond its instances? Here's a suggestion. Suppose that we had a full description of the present, a complete list of the world's intrinsic properties. Would removing a given Lucretian property, such as the property of having previously contained dinosaurs, make a difference to this list? If not, then such properties are dismissible. Following this line of thought, we might place the following condition on truthmaking:

DIFFERENCE- MAKING Any legitimate truthmaker or supervenience base for truths makes a difference to the intrinsic nature of the world.

For the interpretation of TRUTHMAKER in terms of difference making, see for example Lewis (2001) and, for the suggestion of restricting the requirement of difference making to intrinsic natures, see Cameron (2011). DIFFERENCE- MAKING isn't the only way of interpreting the demonstrative imagery in the Sider quotation, and I shall consider later the adequacy of the condition as a prohibition against cheating. For now however, let us take DIFFERENCE- MAKING as a working proposal.

One last observation. I shall assume that there are truths about the past. That is, I assume

PAST REALISM Some claims about the past are true.

PAST REALISM is intuitively attractive. Indeed, the move of denying that claims about the past are true is anathema to many. Dummett (2004, p. 44), for example, calls the view "repugnant." And Armstrong (1997, p. 145) tells us that "[s]urely there are truths about the past.... Only a very extreme sceptic could call this truth into question." There have been, however, serious attempts to reject PAST REALISM. Markosian (2004), for example, holds that past claims are untrue and, drawing on Sider's (1999) notion of quasi-truth, that they are quasi-true or false for only philosophical reasons. And, as I shall note in Sect. 7, some variants of presentism also reject PAST REALISM. For the moment, however, these moves need not concern us. For of course, the tension between PRESENTISM and TRUTHMAKER, and the strategy to resolve this tension by appealing to distributional properties, only arises under the assumption of PAST REALISM.

We have then a prima facie tension among PRESENTISM, TRUTHMAKER, PAST REALISM and DIFFERENCE- MAKING. In response, some reject or restrict TRUTHMAKER: see for example, Merricks (2007). Others reject PRESENTISM: see for example, Sider (2001). And still others attempt a reconciliation. These authors attempt to show that PRESENTISM, TRUTHMAKER, PAST REALISM and DIFFERENCE- MAKING (or some other variant on a prohibition against cheating) are consistent. One recent reconciliatory strategy appeals to distributional properties.

\section{Distributional properties}

Certain properties are distributional. For example, being red all over is a property which, when instantiated, is uniformly distributed over a surface. Other distributional 
properties are non-uniform. For example, being polka-dotted red on white is a colour property which, when instantiated, is non-uniformly distributed over a surface. Being hot on one end and cold on the other is a temperature property distributed over a solid.

It may seem that non-uniform distributional properties are equivalent to a set or arrangement of non-distributional or uniform distributional properties. Consider being polka-dotted red on white. Parts of the surface are red and other parts, white. The surface is polka-dotted but, it may well seem, not in virtue of having some property over and above being red and white in a certain way. For one might think of the parts of the surface that are wholly red as having the uniform distributional property of being red all over and the parts of the surface that are wholly white as having the uniform distributional property of being white all over. Indeed, when we go down to point-sized parts of the surface, we reach non-distributional properties of being red and being white. So the property of being polka-dotted red on white is equivalent to the non-distributional properties of being red and being white, along with a certain arrangement or spatial relationship.

Parsons (2004) however argues that at least some non-uniform distributional properties are irreducible - that is to say, some are not necessarily co-extensive with nondistributional or uniform distributional properties. Consider a cloth that is red on the left edge, blue on the right edge and varies continuously from the one colour to the other through a spectrum of purples. The cloth is dark on the top edge and pale on the bottom edge and varies continuously in tint from dark to pale across its surface. So the cloth has the distributional property of ranging through a continuous spectrum between dark red on one corner and pale blue on the other corner. Every extended part of the cloth has a non-uniform distribution of colours or tints. One might attempt to offer a reduction similar to the one offered above for the property of being polkadotted red on white. The spectral distribution then would be explicated in terms of an arrangement of non-distributional properties: the cloth is a specific red at one point, a specific purple at another point, and so on.

The alleged reducibility of this distributional property appears to depend on there being unextended parts of the cloth. (I shall modify this claim later.) The reduction thus requires that the cloth not be composed of gunk. Any part of gunk has itself proper parts. So gunk is divisible all the way down: gunk is not composed of mereological atoms. For the classic discussion of gunk, see Lewis (1991). Were the cloth spatially gunky, we would never reach points possessing the non-distributional properties of being red or being purple. Notice that the non-equivalence of distributional properties to nondistributional properties requires the mere possibility of gunk with respect to whatever extension over which the property distributes. If spatial gunk is even possible, then the distributional property of ranging through a continuous spectrum between dark red and blue is not necessarily co-extensive with a set of non-distributional colour properties possessed by any number of points on the surface of the cloth, along with an arrangement or spatial relation which obtains among these points. It is widely held that gunk is metaphysically possible. And so not all non-uniform distributional properties are reducible to non-distributional properties.

These considerations yield a strategy for establishing the irreducibility of distributional properties: 
GUNK

To show that some properties non-uniformly distributed over a given extension are not necessarily co-extensive with any set of non-distributed properties, show that gunk with respect to that extension is metaphysically possible.

With this discussion in the background, I turn to the appeal to distributional properties within the philosophy of time.

\section{Distributionalism}

Although the above examples of distributed properties involve a distribution over a spatial extension, the notion of a distributional property is applicable to distributions over other kinds of extension. In particular, one might view certain properties as distributed over times. Cameron (2011, p. 63) provides a useful toy example.

Consider a simple world consisting of just one spatial dimension and one temporal dimension. There is one entity in this world - Flatty - who starts off his life at time $t$ as a point, but who as time progresses grows continuously in one direction of the one spatial dimension he occupies. After the beginning of this life, then, he is no longer a point but a line; and at each moment he is a longer line than he has ever been previously. Exactly one year later, at t*, Flatty tragically ceases to be, and the world is empty.

Flatty's life might be described as instantiating a triangular property distributed over time. Let's distinguish the distributional property from its point features. Flatty has various lengths at different moments of his life. Each length is a point feature. Yet Flatty has one and the same distributional property at each moment of his life. To give another example, one might view my growing up as the distributional property of being initially a child and then an adult. I had the point feature of being a child and now have the point feature of being an adult. But according to the proposal at hand, I have now one and the same distributional property as I had then, a property of maturation distributed over time.

Distributional properties have been used in a response to the truthmaker challenge to presentism. Cameron $(2008,2011)$ proposes that such properties could serve as presently existing truthmakers for past truths. My being initially a child and then an adult is a presently existing property which may serve as a truthmaker for both the present truth that I am now an adult and the past truth that I was before a child. Likewise, one might deny that the world presently possesses the tensed property of once having contained dinosaurs yet hold that the world possesses the presently existing distributional property of once containing dinosaurs and now lacking dinosaurs. Past truths supervene on such properties. So the proposal satisfies PRESENTISM, PAST REALISM and TRUTHMAKER. (As I shall discuss in Sect. 5, Cameron contends that the proposal conforms to DIFFERENCE MAKING.) Call this position distributionalist presentism or, for short, distributionalism.

Distributionalism has met with several objections. Merricks (2008, p. 330) objects to the proposal on the grounds that the presentist must hold that a temporal distributional property distributes over a non-existing extension: 
presentists should deny that persistence is extension throughout a temporal region, subregions of which are various times. So they should reject the view that persisting objects are extended throughout nonexistent regions. (And what a bad view that would be!)

Merricks does not elaborate why a distribution over a non-existent extension would be a bad view. Tallant and Ingram (2012a, p. 269) might be read as developing the objection:

The cost of such a view [i.e., distributionalism] is too high. The distribution of a property requires a region into which it is to be distributed. Once more: an object cannot be polka-dotted (or bear the SDP [i.e., spatially distributional property] being-polka-dotted) without being extended in space. The SDP must distribute and if there is no spatially extended region of its bearer into which it can distribute, then the SDP cannot be instantiated. In the same way, a TDP [i.e., temporal distributional property] can only distribute if its bearer has some existing temporal extension into which it may distribute. It is a substantial cost of any thesis if it requires us to deny this.

Tallant and Ingram thus take the distributionalist to be caught in an inconsistency: temporal distributions require extensions of time, but presentists must deny that there are such extensions.

Cameron responds that a presentist is already committed to a distribution or extension over nonexistent periods. For the life of a presently existing persisting object is extended over a range of time, and the presentist holds that nonpresent times are nonexistent. Addressing the objection that temporal distributional properties are distributed over nonexistent periods, Cameron (2011, p. 72) writes that

the presentist is already committed - simply qua presentist - to denying something akin to the intuition driving this objection, and so even if it is a cost to deny it, it's a cost she has to pay simply to be a presentist: there is no further cost to being a presentist truthmaker theorist.

Tallant and Ingram (2012a) respond that the commitment of the distributional presentist to distribution over nonexistent regions is not one already incurred by presentism. They argue that presentism is not inconsistent with the truth

Extended entities exist iff regions exist for them to distribute across but only with the falsehood

Entities that have existed, exist and will exist do so iff regions exist for them to distribute into or across.

Tallant and Ingram claim that it is the former thesis which is inconsistent with distributionalism. Tallant and Ingram are correct that a presentist generally is not committed to holding that certain properties are distributed over non-existent regions. But they, along with Merricks and Cameron, are mistaken that the distributionalist is so committed. 
An analogy with the topic of persistence may be helpful. Although perdurantism is often presented as the position that things persist by having temporal parts, the mereology is dispensable. Mereologies tend to include among axioms weak supplementation: something is a proper part of a whole only if there is a remainder-that is to say, only if there exists another proper part of the same whole. So talk of temporal parts suggests that things persist in virtue of consisting of a succession of distinct existing objects. But one may be a perdurantist, identifying the persisting thing with a sequence of distinct objects, without being committed to these objects being parts and so without being committed to there existing more than one such constituent object. The perdurantist need hold only that what is present at any given moment is not the whole entity. Things persist in virtue of consisting of a succession of distinct objects; and this is true even if, at any one time, only one of the objects exists. For this reason, talk of temporal parts is misleading and inessential to perdurantism. The perdurantist instead may speak of temporal stages. Such talk is motivated in part by the uncontroversial observation that stages need not conform to an analogue to weak supplementation. A process may consist of a succession of stages even if at any given moment only one stage exists. Notice that, for these reasons, perdurantism is consistent with presentism.

Talk of a distributional property being distributed over an extension is similar. Such talk suggests that a property is distributional only if there is an existing region over which the property is distributed. But this talk is dispensible. Just as the perdurantist is not committed to the mereology implied by talk of temporal parts, so too distributionalism is not committed to the existence of regions as implied by talk of extensions. The distributionalist need only hold that it is one and the same property which, although instantiated at different times, yields distinct point features. So Merricks and Tallant and Ingram are wrong to take the question to be whether the distributional property is extended over nonexistent regions. This is not the nub of the issue. The question of the suitability of temporal distributional properties is not whether the property distributes over existent regions. In the next section, I shall argue that the question is instead the relationship obtaining between the distributional property and certain non-distributional or uniformly distributional properties.

\section{Distributionalism and the challenge}

Are temporal distributional properties legitimate truthmakers? Under what conditions do such properties conform to the prohibition against cheating? In this section, I shall argue that temporal distributional properties meet this requirement just in case they are not reducible to non-distributional or uniformly distributional properties. For readability, let me say that temporal distributional properties are reducible or irreducible, and leave the reference to that to which they are or are not reducible, non-distributional or uniformly distributional properties, tacit.

Recall, one interpretation of the prohibition against cheating is DIFFERENCEMAKING, the requirement that a truthmaker makes a difference to the intrinsic nature of the world. First notice that, even if a temporal distributional property reduces to, or is necessarily co-extensive with, non-distributional or uniformly distributional properties, then the distributive property can satisfy DIFFERENCE- MAKING. Suppose that 
the distributional property of my being initially a child and then an adult reduces to an arrangement of the properties of being a child and being an adult. Then the conjunctive property being initially a child and then an adult satisfies DIFFERENCE- MAKING. For this reason, temporal distributional properties can satisfy DIFFERENCE- MAKING, and so be, according to this condition of adequacy, legitimate truthmakers for past truths, even if they are not irreducible.

However, in our example only the component of being an adult in the distributional property of my being initially a child and then an adult is a difference maker to my present intrinsic nature. Furthermore, the truth that I was once a child is explained not by the distributional property of my being initially a child and then an adult but by the property of being initially a child, a property which I no longer instantiate. The property of being initially a child is presently inert. The conjunct of the property that makes the past claim true (or on which the past truth supervenes) is not the conjunct that makes a difference to my present intrinsic nature. Moreover, the property of being initially a child appears to be past directed in the way in which the Lucretian properties are past directed. Recall, the claim that the world presently instantiates the property of having contained dinosaurs ascribes to the world a property which points beyond its instantiation. So too the claim that I currently instantiate the property of being initially a child appears to ascribe to me a property which points beyond its instantiation. And so the distributional property, if conjunctive and so reducible, is partly a cheater.

It is due to these considerations that DIFFERENCE- MAKING is not equivalent to a prohibition against cheating. For a conjunctive property may be both a difference maker and a cheater, if for example one conjunct satisfies DIFFERENCE- MAKING but the other points beyond its instances. We can amend the requirement to exclude this counterexample:

REVISED DIFFERENCE- MAKING

Any truth-functional constituent of a legitimate truthmaker or supervenience base for truths makes a difference to the intrinsic nature of the world.

Talk of truth-functional constituents in this context is rough and ready but serves our purposes. On this way of speaking for example, a binary conjunctive property or an implicative property both have two constituents. REVISED DIFFERENCE- MAKING captures the sense in which temporal distributional properties, if reducible to a conjunction of non-distributional or uniformly distributional properties, cheat. If my being initially a child and then an adult consists in part in my being initially a child, then the complex property fails REVISED DIFFERENCE- MAKING since only one constituent makes a difference to the world's intrinsic nature.

Caplan and Sanson (2011, p. 201) hold that the distributionalist fails to satisfy a prohibition against cheating even if the temporal distributional property is irreducible. But I believe this to be mistaken. Let's continue our example of maturation. The distributionalist move is to assert that I am currently an adult not in virtue of instantiating some non-distributional or uniformly distributional property of adulthood. I am currently an adult in virtue of instantiating an irreducible non-uniformly distributional property of maturation. I was once a child in virtue of instantiating the same property. The property in virtue of which I was once a child is the very property in virtue of which I am now an adult. So maturation points beyond its instances neither wholly nor in part. 
Irreducible temporal distributional properties satisfy the intuitive gloss on a prohibition against cheating. Moreover, we have seen that temporal distributional properties satisfy DIFFERENCE- MAKING. And, since irreducible temporal distributional properties are themselves atomic properties, they satisfy REVISED DIFFERENCE- MAKING. So irreducible temporal distributional properties conform to all of DIFFERENCE- MAKING, REVISED DIFFERENCE- MAKING and the intuitive demonstrative guide to a prohibition against cheating.

These considerations give us good reason to hold that non-uniform temporal distributional properties satisfy non-cheating requirements only if they are irreducible to non-distributional and uniformly distributional properties. So the viability of distributionalism, as a solution to the truthmaker objection to presentism, hinges on their irreducibility.

\section{Against distributionalism}

Cameron (2011) considers the worry that temporal distributional properties are reducible to non-distributional properties and, in response, simply stipulates their irreducibility. Discussing the move of taking a temporal distributional property to be equivalent to a complex conjunctive property, some conjuncts of which are simple present tensed properties like is an adult and others of which are the past-directed properties like was a child, he (2011, p. 70) writes:

The point of appealing to distributional properties is that this move can't be made. Distributional properties cannot be broken up into simple components: there is just one property here, and it is fundamental - and it is exactly the same property that is grounding truths about how the bearer now is that is grounding truths about how the bearer was. There is one fundamental property that is involved both in past settling and in difference making, and so there is no sense in which we are appealing to a solely past-directed property in our truthmaking.

On what grounds can the distributionalist make this stipulation? It can be difficult to adjudicate on such matters. One philosopher's bold conjecture is another's undefended assumption. However, in this case the onus is clearly on the distributionalist to defend the stipulation. Some of our examples of temporally distributed properties appear to be conjunctive properties and so prima facie not irreducible. For example, the property of having been a child and being now an adult appears to be explicable in terms of the properties of being a child and being an adult, along with a temporal arrangement of these properties.

The characterization of maturation as a binary conjunction of two uniform temporal distributional properties is of course a simplification. Maturation is arguably a continuous infinite series of point features. Likewise, Flatty's growth appears to be a continuous series of line segments. But even if we hesitate to represent such a series with an infinitary conjunction, a continuous series is reducible to an infinite set of uniform distributional or non-distributional properties. It appears, then, that maturation just is a series of age features, and Flatty's growth, a series of lengths. I shall return to the contrast between continuity and what is needed to establish irreducibility in Sect. 
7. For now it suffices to note that the onus is on the distributionalist to provide an argument for the irreducibility of non-uniform temporal distributional properties.

Parson's argument that distributional properties are not in general equivalent to nondistributional properties, is not available to the presentist. Recall, the argument that a given distributional property is not necessarily co-extensive with a non-distributional property requires the possibility of gunk with respect to the extension over which the distributional property distributes. Parson's examples concern spatial extension. But the strategy for establishing the irreducibility of a given distributional property, GUNK, ought to be applicable to any kind of extension. The presentist, however, must reject the possibility of temporal gunk. For PRESENTISM is committed to the instantaneity of existence. What exists, according to the presentist, is temporally unextended. (I shall modify this claim in Sect. 7.) Were the present to have duration, then the present would be divisible. And, were the present divisible, it would be divisible into distinct times. And so some parts of the present would be earlier and others later, since presentists agree that divisions of temporal regions are ordered by earlier than and later than relations. It is absurd that some times would be earlier than others, yet both present. The presentist thus appears committed to the claim that the present is durationless.

I do not know of a good argument against this commitment. Hastevold (2008, p. 331) argues that the present cannot be durationless:

the Presentist should allow that one can presently believe the simple proposition that one presently exists, but it is dubious ... that one can entertain, much less affirm, the proposition that one presently exists 'within the space of an instant'; believing the simplest of propositions seems to 'take time'.

Perhaps Hastevold's considerations show that an entity that exists merely for an instant could not entertain or express the proposition expressed by 'I presently exist'. Even this makes an assumption about thought which is not obviously correct. But if we concede that thoughts can only be entertained over a period of time, this falls short of establishing that the present has a duration. For surely the proposition that I exist only at the present instant may be true even if I cannot entertain or subvocalize a belief in that proposition in an instant. A similar response can be made to McKinnon (2003) who argues that since neural processes have duration, the presentist is committed to denying mind-body identity theory.

Others attempt to show that arguments for thin presentism are unpersuasive. Such arguments are venerable. For example, Augustine argues that were the present to have duration then it would be divisible into distinct but simultaneous times, on pain of contradiction. McKinnon (2003, p. 307) reconstructs the argument:

If the present is extended then it has wholly distinct parts and those parts must be simultaneous. This rests on the assumption that if $\mathrm{x}$ and $\mathrm{y}$ are both metaphysically present then they are simultaneous. On the other hand, if the present is extended then it also seems that its disjoint parts cannot be simultaneous: if $\mathrm{x}$ and $\mathrm{y}$ are not temporally overlapping then they are temporally separated and hence, not simultaneous. Thus we have a reductio of the view that the metaphysical present is extended. 
McKinnon (2003, p. 318) claims that the Augustinian argument is guilty of an equivocation: 'simultaneous' can mean occurring at the same moment of time or being distinct parts of the same thick present. McKinnon may be correct that when I speak of the present, I typically refer to a duration of time; the context of my utterance determines the extent of this duration. But, for any durational present, the further question can be asked for any two given parts, is the one part prior to the other? One may thereby shift the context from the question of simultaneity in the latter sense to that of the former sense. It is uncontroversial that the latter has duration. The considerations brought forward by the thick presentist fail to establish that the argument that the present in the former sense lacks duration is unsound.

Finally, some have held that, although the present lacks duration, presentists are not committed to the instantaneity of existence. Merricks (2007, p. 124), for example, holds that the saddling of presentism with the instantaneity thesis is a mistake, writing that "[p]resentists deny that everything is instantaneous; they think that many objects not only exist, but also have existed and will exist." Certainly, presentists accept the legitimacy of tensed talk. They allow that we can say, for example, 'Caesar existed' or 'Yesterday lasted 24 hours'. But they deny the ordinary reading of these claims, under which 'Caesar existed' carries ontological commitment to Caesar and 'Yesterday lasted 24 hours' entails that yesterday had a duration. On the contrary, presentists deny that past claims carry their ordinary commitments. To put the point somewhat colloquially, to have existed is not a way of existing but a way of not existing. Presentists have several options for how to read past and future claims; I shall discuss these in Sect. 7. But regardless of how presentists interpret past and future claims, they do not have the option of taking existence to have straightforwardly a duration.

So presentists ought to deny that the temporal extension of objects is possibly gunky. Indeed, under the plausible assumption that at least some things presently exist, PRESENTISM just is the view that existence is temporally indivisible. As such, Parson's argument for the irreducibility of some temporal distributional properties is unavailable to the presentist. Notice that this objection is not the complaint raised in Sect. 5, the misplaced worry that temporal distributional properties are distributed over nonexistent regions. This objection, recall, lapses if the property is not reducible to an arrangement of nondistributed properties. Rather, the objection of this section questions not the existence of temporal distributional properties but their irreducibility.

\section{Responses and replies}

In this section, I shall consider a few responses to the objection raised in Sect. 6.

You claim that the presentist is committed to the present being durationless or temporally unextended. But one might hold that the present is an extended simple. Such a present moment would have duration but would not be divisible into smaller durations. A temporal distributional property might be thought of as being distributed through such a present.

Notice that embracing the thesis that the present is an extended simple will not allow the distributionalist to appeal to gunk so to show that temporal distributional proper- 
ties are irreducible. Nothing in the discussion of the previous sections hinged on the present being unextended. The difficulty for the presentist, however, is not that she is committed to the present being unextended, but that she is committed to the present being indivisible. For GUNK requires that the dimension or extension over which a distributional property is distributed is possibly gunky: it is possible that each part of that extension itself has at least one proper part. But if the present is either necessarily durationless or necessarily indivisible, then this premise of the argument, applied to the extension of time, is false.

Nonetheless, the distributionalist who holds that the present is an extended simple has available to her an alternative strategy for establishing that there are irreducibly distributional temporal properties. For a presently existing property may be distributed over the extended but indivisible present. And indeed, as such properties would be extended over an indivisible duration, they would not be reducible to nondistributional properties. However, this strategy will not help the distributionalist to provide presently existing truthmakers for past claims. For taking the present to be an extended simple only shows that there may be irreducibly distributional properties distributed over the extended but indivisible duration of any one moment, not that the properties distributed over a divisible duration of time are irreducible. And it is only these latter properties which can provide presently existing truthmakers for past claims.

One might endorse PRESENTISM, and so hold that the only existing objects are presently existing objects, but deny that the only time which exists is the instantaneous present. Then the strategy of GUNK is available to the distributionalist.

One way of cashing out this position is as follows: hold that time is temporally gunky but there is a minimal interval of time during which an object can exist. Call such an interval a minimum. Minima have temporal parts all the way down: any temporal part of a minimum has itself temporal parts. However, no object can exist during only a proper part of a minimum. The metaphysical possibility of objects having a minimal duration of existence is not implausible. On this view, all properties are temporally distributed over at least a minimum. Since the minima are allegedly possible, distributional properties do not necessarily reduce to non-distributional properties.

This response will not help the distributionalist. The view that there are minima and that all objects exist solely during the present minima (while perhaps having existed earlier and yet will exist later) is consistent with the claim that the only existing objects are presently existing objects. But these objects occupying the present minima typically also exist in the very recent past and future. Compare this situation with the view that all objects exist at all times. Here too the only existing objects are presently existing objects but objects also exist in the past and the future. And so an argument to show that distributional properties are not in general equivalent to non-distributional properties, is still not available to the presentist.

Suppose that I have the property of being first a child and then an adult. This property, given my age, determines that I am now an adult. This is not equivalent to just possessing the property of being an adult now. For I possess the distributional property over a region of time which includes the present. Take any subregion that also includes the present. The subregion is an extended period 
or duration of time that is a proper part of the original region. That subregion can itself be divided into proper parts, one of which contains the present. So no matter how small a period of time surrounding the present one considers, over which my maturation property is spread, we can choose a smaller period of time surrounding the present, over which my maturation property is spread. These regions of time are largely composed of nonexistent periods of time, but they all include the present. And the distributional presentist, as has already been noted, should not be worried that certain properties are as it were distributed over nonexistent regions.

This response confuses continuity with gunkiness. The feature canvassed is that no matter how small an extension one considers, over which the property distributes and which includes a given point, we can choose a smaller extension, over which the property distributes and which also includes that point. This feature is not gunkiness. An extension is gunky just in case any part of that extension has proper parts. Moreover, continuity cannot replace gunkiness in an argument for the irreducibility of temporal distributional properties. The presentist may allow that, loosely speaking, the present minute is a part of the present hour. But a presentist, I have argued, is committed to holding that the present strictly speaking is an indivisible instant.

The ersatz presentist can appeal to the strategy GUNK so to establish that temporal distributional properties are irreducible to uniform distributional or nondistributional properties. Ersatz presentists hold that expressions apparently referring to past times and past objects in fact refer to abstract objects representing past times and objects. Such abstracta are ordered by relations analogous to the earlier than, later than and simultaneous with relations-merely analogous to these relations since, of course, the ersatz past objects are not themselves times and so do not stand in temporal relations.

The appeal to ersatz 'times' is not, I believe, the strategy labeled GUNK, since GUNK appeals to times, real times, the sort you can be on, waste or have the best of your life, not abstract objects. Ersatzists of course claim that talk of past times just is talk of abstracta. But this claim may be taken in one of several ways; no version of ersatzism will help the distributionalist.

One version of ersatzism is presentist fictionalism. Lewis (1986, p. 203-204) canvasses this kind of presentism as a response to the Problem of Temporary Intrinsics; on this line:

the only intrinsic properties of a thing are those it has at the present moment. Other times are like false stories; they are abstract representations, composed out of the materials of the present, which represent or misrepresent the way things are. When something has different intrinsic properties according to one of these ersatz times, that does not mean that it, or any part of it, or anything else, just has them.

Such ersatzists take claims about the past to be fictions and so, strictly speaking, false. Since fictionalists deny PAST REALISM, they have no need for presently existing truthmakers for past claims. Fictionalism is not an option for the distributionalist. 
According to a second version of ersatzism in the philosophy of time, there are truths about the past but such truths carry little existential commitments. Such a presentist views true past claims as true representations of the way things were. We require presently existing objects to represent past objects, but the truths are not made true by such abstracta. Merricks (2007) may be this kind of presentist. Such presentists reject TRUTHMAKER and so of course do not need temporal distributional properties.

A third version of ersatzism in the philosophy of time is exemplified by such authors as Bourne (2006) and Crisp (2007), who hold that past claims are true and are made true by the presently existing abstracta which represent past objects. Past truths supervene on such abstracta. Such presentists accept all of PRESENTISM, TRUTHMAKER and PAST REALISM. But since such ersatzists have truthmakers available to them, they also need no truck with distributional properties. ${ }^{4}$

According to a somewhat similar variant of presentism, past objects are presently existing nonconcrete objects. Linsky and Zalta (1994, 1996) and Williamson (1998) develop such a line in the metaphysics of modality. I might have had a sister. This truth is grounded, on this view, on an actually existing nonconcrete object which possesses the modal property of possibly being both a concrete object and my sister. Williamson (1998, pp. 265-266) canvasses applying such a strategy to the philosophy of time. On this line, a merely past object such as Caesar presently exists but is no longer concrete. Unlike the views of Bourne (2006) and Crisp (2007), this position is not a version of ersatzism, since the presently existing abstract Caesar is numerically identical with the formerly concrete, living and breathing, person. But such presentists also have readily available truthmakers for past truths, and so do not need to appeal to temporal distributional properties. ${ }^{5}$

You have argued that it is not available for the presentist to hold that time is gunky, since presentism is committed to the instantaneity of the present. But we might view the presentist as only making a claim about what is actually the case.

Such a version of presentism is consistent with the possibility of temporal gunk.

In this response, my interlocutor motivates the irreducibility of distributional properties from an alternative view of the modal status of PRESENTISM. The position is unorthodox. A standard view among metaphysicians is that a metaphysical claim, if true, is necessarily true. There is, however, growing interest in this nonstandard approach to the modal status of metaphysical claims: Rosen (2006) and Miller (2009, 2010), for example, argue that certain metaphysical theses are contingently true. Cameron (2007) himself argues that some truths about composition are contingent. And others embrace contingentism about time. Bourne (2006, p. 220-230), for example, argues that although A-theory is actually true, there are metaphysically possible worlds where temporal events are merely B-related.

This is the most promising line of response for the distributionalist. I have argued that the distributionalist must show that the talk of temporal distributional properties

\footnotetext{
4 Caplan and Sanson (2010) argue that such abstracta do not ground past truths and so this version of ersatzism fails a truthmaker requirement stronger than TRUTHMAKER.

5 For discussion of the contingently nonconcrete, see Bennett (2006) and Nelson and Zalta (2009).
} 
is not simply short hand for talk of nondistributional or uniformly distributional properties. To show this, it suffices to establish that temporal distributional properties are not necessarily equivalent to nondistributional or uniformly distributional properties. And I have raised doubts about whether the presentist who holds that PRESENTISM is necessarily true can establish this. But grant for the moment that PRESENTISM is contingently true. Then it seems that the contingent distributionalist can establish that temporal distributional properties are not necessarily equivalent to nondistributional or uniformly distributional properties, since she is free to hold that there are nonactual but metaphysically possible worlds where time is gunky and not everything is present. In this way, the contingent distributionalist can make a straightforward appeal to GUNK in order to offer a presently existing truthmaker which conforms to REVISED DIFFERENCE MAKING. So a take-away from this article is that one can reconcile PRESENTISM and TRUTHMAKER in this fashion by holding that PRESENTISM is contingently true. However, I hesitate to conclude that a presentist ought to be a distributionalist. For contingent presentism faces considerable challenges.

One such challenge is to explain our epistemic access to metaphysical truths, if contingent. Metaphysics appears to be largely an activity from the armchair. Yet it is unclear how one could come to know contingent truths by such a method. Rosen sketches one kind of response to this challenge. ${ }^{6}$ He argues that correctly conceivable worlds (roughly: conceivable worlds where the actual a posteriori necessities are true) are metaphysical possible worlds yet correct conception underdetermines many metaphysical positions. Metaphysical theories are determined instead in part by such $a$ priori theoretic desiderata as economy, fecundity, plausibility and immunity to counterexample. So Rosen holds that certain metaphysical theses are contingent a priori truths, of a kind distinct from considerations of indexicality or reference-stipulation. To develop this line may yield a satisfying response to the epistemic challenge.

But even if the contingent presentist can meet this first challenge, she cannot straightforwardly use GUNK to show that temporal distributional properties are irreducible. Here's why. Even the contingent presentist ought to accept that metaphysical truths are nomologically necessary. ${ }^{7}$ Just as a true physical theory defines what is physically possible, so too an actually true metaphysical thesis delineates a space of worlds where that thesis is true. The contingent presentist holds that there are correctly conceivable worlds that lie outside this space. But from these considerations, GUNK is ambiguous between two senses of metaphysical possibility, a notion of what is possible according to the actual metaphysical truths, analogous to scientific nomological possibility, and a notion of what is correctly conceivable. We might disambiguate as follows:

NARROW GUNK To show that some properties non-uniformly distributed over a given extension are not necessarily co-extensive with any set of non-distributed properties, show that gunk with respect to that extension is metaphysically possible according to the actual metaphysical truths.

\footnotetext{
${ }^{6}$ For an alternative approach to the epistemology of contingent metaphysical truths, see Miller (2010).

7 For criticism of this construal of metaphysical necessity, see Williams (2006).
} 
To show that some properties non-uniformly distributed over a given extension are not necessarily co-extensive with any set of non-distributed properties, show that gunk with respect to that extension is correctly conceivable.

Of course, to unpack NARROW and BROAD GUNK would require fuller explication of what constitutes metaphysical truth and correct conception. But suppose for the moment that these two notions of necessity diverge.

It is NARROW GUNK which is the relevant variant of a strategy to establish that temporal distributional properties are irreducible. Let me pursue a little further the analogy between scientific and metaphysical necessity. Notice that those properties are irreducible within natural science which are necessarily irreducible according to a scientific-nomological construal of necessity. That is to say, a property $\mathrm{P}$ is not reducible to $\mathrm{Q}$, according to physical science, just in case $\mathrm{P}$ and $\mathrm{Q}$ are not extensionally equivalent in some world where the actual physical laws hold. By analogy, one might well hold that those properties are irreducible within metaphysics which are necessarily irreducible according to the metaphysical-nomological construal of necessity. That is to say, a property $\mathrm{P}$ is not reducible to $\mathrm{Q}$, according to metaphysics, just in case $\mathrm{P}$ and $\mathrm{Q}$ are not extensionally equivalent in some world where the actual metaphysical truths obtain. If this is correct, then it is the narrower notion of necessity which is relevant to establishing the metaphysical irreducibility of a property.

But moreover it seems plausible that PRESENTISM, if true, is a metaphysical truth. The relevant worlds for establishing the irreducibility of a temporal distributional property are then those worlds where PRESENTISM is true. Correctly conceivable worlds where presentism is false are irrelevant for establishing the irreducibility of a temporal distributional property. And so it is NARROW GUNK which is relevant to establishing whether a temporal distributional property is irreducible. And, for the reasons given in Sect. 6, temporal distributional properties cannot be established as irreducible by the strategy of NARROW GUNK.

The distributionalist might respond in one of two ways. She might deny that presentism, if true, is a metaphysical truth. Or she might argue against the argument just sketched so to defend the claim that it is BROAD GUNK which is relevant to establishing the metaphysical irreducibility of a temporal distributional property. I cannot here develop in full the argument sketched above that it is the nomological construal, and not correct conception, which provides the more fruitful characterization of metaphysical necessity. And so I do not claim that the distributionalist cannot respond to the challenge TRUTHMAKER poses for PRESENTISM by embracing the view that PRESENTISM is contingently true. But I do hold that merely showing that there is a sense in which presentism is contingent does not suffice to establish the viability of distributionalism. There is more work to be done.

Here's a final response.

You merely show that GUNK, one strategy for establishing the irreducibility of distributional properties, is unavailable to the presentist. She may employ some other strategy or simply stipulate their irreducibility. 
True, I have not shown that the presentist is committed to denying that temporal distributional properties are irreducible. But I have argued in Sect. 6 that distributional properties prima facie appear to be equivalent to non-distributional or uniformly distributional properties. For example, the property of having been a child and being now an adult appears to be explicable in terms of the properties of being a child and being an adult, along with an arrangement of these properties. And although having been a child and being now an adult is but a toy example, the appearance of reducibility is easily extended. For example, Flatty's growth appears to be a series of lengths. So stipulation of the irreducibility of temporal distributional properties is prima facie unpersuasive.

The distributionalist might respond that her move just is to stipulate that, despite appearances to the contrary, temporal distributional properties are irreducible. Generally, stipulation is a less than ideal philosophical strategy. For one thing, stipulation would not persuade one opposed to the distributionalist's position that distributionalism is true. But it may seem to the reader that the stipulation that temporal distributional properties are irreducible is not intended to persuade anyone of the truth of distributionalism. Rather, the stipulation is aimed to show that PRESENTISM and TRUTHMAKER can be reconciled without running afoul of a prohibition against cheating such as REVISED DIFFERENCE MAKING. And so even if the stipulation of the truth of distributionalism does not on its own provide positive reasons to be a distributionalist, the stipulation that temporal distributional properties are irreducible can show that the challenge to PRESENTISM posed by TRUTHMAKER can be met.

I believe that the stipulation cannot respond adequately to the challenge to PRESENTISM posed by TRUTHMAKER. For the stipulation is of a kind with a clearly unpersuasive line of reponse to the challenge, the assertion that Lucretian properties are not cheaters. The distributionalist may respond that there is a salient difference between the two cases. In the one case, Lucretian properties are stipulated as making an intrinsic difference in the world; in the other case, temporal distributional properties are stipulated to be irreducible. The former case is clearly an unhappy response to the objection that Lucretian properties do not appear to make a difference in the world and so are cheaters. It may seem that the latter case is not the same kind of simple denial- that it is not the mere stipulation that tensed properties are non-cheaters. But either stipulation has this immediate consequence. The stipulation that Lucretian properties are difference makers simply is the stipulation that they are not cheaters, given the relation between difference making and cheaters, which I argued for in Sect. 5. So too the stipulation that temporal distributional properties are irreducible simply is the stipulation that they are not cheaters, given the relation between reducibility and cheaters, which I argued for in Sect. 5. For these reasons, the stipulation that temporal distributional properties are irreducible is unpersuasive as a response to the challenge TRUTHMAKER poses for PRESENTISM.

To make the point differently, grant for the sake of argument that the stipulation is an adequate response to the challenge. If I am right that the stipulation that temporal distributional properties are irreducible is of a kind with the stipulation that Lucretian properties are difference makers, then the stipulation that temporal distributional properties are irreducible undercuts the motivation for distributionalism. For were it permissible to to stipulate that temporal distributional properties are irreducible, then it would be 
no less permissible to stipulate that Lucretian properties are difference makers. But if it is permissible to stipulate that Lucretian properties are difference makers, then the Lucretian can meet the challenge TRUTHMAKER poses for PRESENTISM, and there is no reason to embrace distributionalism. For these reasons, the stipulation that temporal distributional properties are irreducible is either unpersuasive or self-defeating.

Let's sum up. A presentist who wishes to appeal to distributional properties so to give an analysis of change or to provide presently existing truthmakers for past claims may respond by giving us an account of presentism which is not committed to solely instantaneous or temporally indivisible existents. Or she may give us another argument to show that non-uniformly distributional properties are not in general equivalent to nondistributional or uniformly distributional properties, one which does not rely on the possibility of gunk. Or she may defend the nonstandard view that PRESENTISM is contingently true against the objections raised above. Or she may defend the move of stipulating the irreducibility of temporal distributional properties. But in our current state of understanding on these issues, we ought to conclude that the attempted reconciliation of presentism and truthmaker theory by appeal to distributional properties fails.

Acknowledgments Thanks to Paul Audi, Andrew Bailey, Michael Barnard, Troy Cross, Foad DizadjiBahmani, Michael Flood, Alice Kelly, Bernie Linsky, Ioan Muntean, Howard Nye, Joshua Peachment, Tim Put, Jason Raibley, Alex Stiles, Allison Thorton, Chris Tweedt and the audience at a paper delivered at the APA Central, February 2013.

\section{References}

Armstrong, D. M. (1997). A world of states of affairs. Cambridge: Cambridge University Press. Armstrong, D. M. (2004). Truth and truthmakers. Cambridge: Cambridge University Press.

Bennett, K. (2006). Proxy actualism. Philosophical Studies, 129, 263-294.

Bigelow, J. (1988). The reality of numbers: A physicalist's philosophy of mathematics. Oxford: Oxford University Press.

Bigelow, J. (1996). Presentism and properties. Nô̂s, 30, 35-52.

Bourne, C. (2006). A future for presentism. Oxford: Oxford University Press.

Cameron, R. (2007). The contingency of composition. Philosophical Studies, 136, 99-121.

Cameron, R. (2008). Comments on Merricks' truth and ontology. Philosophical Books, 49, 292-301.

Cameron, R. (2011). Truthmaking for presentists. In D. Zimmerman (Ed.), Oxford studies in metaphysics (Vol. 6). Oxford: Oxford University Press.

Caplan, B., \& Sanson, D. (2010). The way things were. Philosophy and Phenomenological Research, 81, 24-39.

Caplan, B., \& Sanson, D. (2011). Presentism and truthmaking. Philosophical Compass, 6, 196-208.

Crisp, T. (2004). On presentism and triviality. Oxford Studies in Metaphysics, 1, 15-20.

Crisp, T. (2007). Presentism and the grounding objection. Nous, 41, 118-137.

Dummett, M. (2004). Truth and the past. New York: Columbia University Press.

Hastevold, H. S. (2008). Presentism: Through thick and thin. Pacific Philosophical Quarterly, 89, 325-347.

Lewis, D. (1986). On the plurality of worlds. Oxford: Basil Blackwell.

Lewis, D. (1991). Parts of classes. Cambridge: Basil Blackwell.

Lewis, D. (2001). Truthmaking and difference-making. Nous, 35, 602-615.

Linsky, B., \& Zalta, E. (1994). In defense of the simplest quantified modal logic. Philosophical Perspectives, $8,431-458$.

Linsky, B., \& Zalta, E. (1996). In defense of the contingently nonconcrete. Philosophical Studies, 84, 283-294.

Lombard, L. (1999). On the alleged incompatibility of presentism and temporal parts. Philosophia, 27, 253-260. 
Markosian, N. (2004). A defense of presentism. In D. Zimmerman (Ed.), Oxford studies in metaphysics (Vol. 1, pp. 47-82). Oxford: Oxford University Press.

McKinnon, N. (2003). Presentism and consciousness. Australasian Journal of Philosophy, 81, 305-323.

Mellor, D. H. (1998). Real time II. New York: Routledge.

Merricks, T. (1995). On the incompatibility of enduring and perduring entities. Mind, 104, 521-531.

Merricks, T. (2007). Truth and ontology. Oxford: Clarendon Press.

Merricks, T. (2008). Replies to cameron, schaffer and soames. Philosophical Books, 49, 329-343.

Meyer, U. (2005). The presentist's dilemma. Philosophical Studies, 122, 213-225.

Meyer, U. (2012). The triviality of presentism. In R. Ciuni, K. Miller, \& G. Torrengo (Eds.), New papers on the present. Philosophia: München.

Miller, K. (2009). Defending contingentism in metaphysics. Dialectica, 63, 23-49.

Miller, K. (2010). Three routes to contingentism in metaphysics. Philosophy Compass, 5, 965-977.

Nelson, M., \& Zalta, E. (2009). Bennett and 'proxy actualism'. Philosophical Studies, 142, 277-292.

Parsons, J. (2004). Distributional properties. In F. Jackson \& G. Priest (Eds.), Lewisian themes. Oxford: Oxford University Press.

Rosen, G. (2006). The limits of contingency. In F. McBride (Ed.), Identity and modality (pp. 13-38). Oxford: Oxford University Press.

Schaffer, J. (2008). Truth and fundamentality: on Merricks's truth and ontology. Philosophical Books, 42, $302-316$.

Schaffer, J. (2010). The least discerning and most promiscuous truthmaker. Philosophical Quarterly, 60, $307-324$.

Sider, T. (1999). Presentism and ontological commitment. Journal of Philosophy, 96, 325-347.

Sider, T. (2001). Four dimensionalism: An ontology of persistence and time. Oxford: Oxford Univerity Press.

Tallant, J., \& Ingram, D. (2012a). Time for distribution? Analysis, 72, 264-270.

Tallant, J., \& Ingram, D. (2012b). Presentism and distributional properties. Oxford Studies in Metaphysics, 7, 305 .

Tooley, M. (1997). Time, tense and causation. Oxford: Oxford University Press.

Williams, J. R. G. (2006). Illusions of gunk. Philosophical Perspectives, 20, 493-513.

Williamson, T. (1998). Bare possibilia. Erkenntnis, 48, 257-273. 